\title{
Effects of laser-ablation target damage on particulate production investigated by laser scattering with deposited thin film and target analysis
}

\author{
H. L. Spindler, R. M. Gilgenbach, ${ }^{\text {a) }}$ and J. S. Lash \\ Intense Energy Beam Interaction Laboratory, Nuclear Engineering and Radiological Sciences Department, \\ The University of Michigan, Ann Arbor, Michigan 48109-2104
}

(Received 19 January 1996; accepted for publication 5 April 1996)

\begin{abstract}
Experiments have been carried out to correlate ablated particulate density and size to the number of $\mathrm{KrF}$ excimer laser $(248 \mathrm{~nm}, 40 \mathrm{~ns},<1.2 \mathrm{~J})$ pulses incident on a single location of a pure solid aluminum target and to relate particulate production to target surface damage. An analysis of laser ablation deposited aluminum films on silicon substrates was used to determine the density of ablated particulate greater than $0.5 \mu \mathrm{m}$ in diameter. For an undamaged target, the laser deposited particulate density was on the order of $8.6 \times 10^{5} \mathrm{~cm}^{-2}$ per 1000 shots. A damaged target (following 1000 laser pulses) produced a density on the order of $1.6 \times 10^{6} \mathrm{~cm}^{-2}$ per 1000 shots on the substrate. Dye laser optical scattering was also used to measure, in real time, the velocity of the particulate and the relative particulate density in the laser-ablation plume versus target damage. Results indicated a rapid rise in the production of particulate as target damage was increased up to 3000 laser pulses; after this number of shots the density of particulate in the laser ablation plume saturated. A peak in the scattered light for each stage of target damage occurred $40 \mu$ s after the initial $\mathrm{KrF}$ laser pulse, translating to a velocity of about $100 \mathrm{~m} / \mathrm{s}$ for the smaller particulate $(<1 \mu \mathrm{m}$ diameter). The later scattered signal, around $160 \mu \mathrm{s}$, was apparently due to the larger particulate $(5-15 \mu \mathrm{m})$, traveling at a velocity of approximately $25 \mathrm{~m} / \mathrm{s}$. Particulate production is related to the formation of laser ablation-induced cones on the damaged targets. (C) 1996 American Institute of Physics. [S0003-6951(96)00123-4]
\end{abstract}

Laser ablation has been demonstrated to be an effective technique for thin film deposition of ceramics, metals, and polymers. ${ }^{1-6}$ The major drawback of laser ablative deposition has been the generation of particulate matter. Various approaches have been used to mitigate laser-ablative particulate in film deposition, including the use of two lasers, ${ }^{7}$ intersecting plumes, ${ }^{8}$ and rotating or rastering the target. ${ }^{9}$ The mechanisms for particulate origination from the laser ablation target are important in order to further reduce its generation. Previous diagnostics of particulate have been primarily sample analysis, ${ }^{1,7,9,10}$ with other real-time measurements utilizing Mie scattering, ${ }^{11,12}$ and gated CCD photography of blackbody radiation. ${ }^{13}$

In this letter, we present real-time laser optical scattering data and deposition sample analysis to systematically investigate the effects of target damage on the generation of particulate. Particulate density has been measured as a function of the number of $\mathrm{KrF}$ excimer laser pulses incident on a single location of the target. Other researchers have long reported the existence of laser-ablative cones on targets. ${ }^{2,14,15}$ It is shown here that the existence of these cones is strongly correlated to enhanced production of particulate.

The analyzed samples consisted of aluminum films deposited on room temperature silicon substrates at pressures less than $4 \times 10^{-6}$ Torr. For the film deposition, a $99.999 \%$ pure solid aluminum target was placed at a $45^{\circ}$ angle to the incident $\mathrm{KrF}$ laser beam. This allowed the $\mathrm{KrF}$ laser ablation plume to be directed perpendicular to the surface of the silicon wafer, which was also at a $45^{\circ}$ angle to the incident

\footnotetext{
a) Author to whom correspondence should be addressed; also in Applied Physics Program. Electronic mail: rongilg@engin.mich.edu
}

beam. The wafer was placed about $1.7 \mathrm{~cm}$ in front of and above the target. The laser ablation plume was produced by focusing a pulse from a $\mathrm{KrF}$ excimer laser $(248 \mathrm{~nm}, 40 \mathrm{~ns}$, $<1.2 \mathrm{~J})$ on the aluminum target. The spot due to the laser was $2.5 \mathrm{~mm}$ by $3.0 \mathrm{~mm}$, or $0.075 \mathrm{~cm}^{2}$ in area. The fluence was measured at regular intervals by inserting a calorimeter in front of the $\mathrm{KrF}$ laser beam. The average laser fluence at the target for the film deposition was $4.3 \mathrm{~J} / \mathrm{cm}^{2}$.

The particulate density in the aluminum films produced from the ablation was investigated by placing each substrate under a camera attached to an optical microscope. The features in the aluminum films were magnified by a factor of approximately 350 in the resulting photographs, allowing particulate with diameters greater than about $0.5 \mu \mathrm{m}$ to be counted.

To further study the density and velocity of particulate in a laser ablation plume, real-time optical scattering data was measured. A KrF laser beam, focused down to a spot 0.06 $\mathrm{cm}^{2}$ in area and with a fluence of $6.4 \mathrm{~J} / \mathrm{cm}^{2}$, produced the laser ablation plume at normal incidence. After an adjustable delay ( $\geqslant 10 \mu \mathrm{s}$ ), a pulse from a $\mathrm{XeCl}$ excimer-pumped dye laser $(540 \mathrm{~nm}, 20 \mathrm{~ns}, \sim 1 \mathrm{~mJ})$ was directed through the plume about $4 \mathrm{~mm}$ in front of the target. A fraction of the light from the dye laser beam was scattered at $90^{\circ}$, from the particulate in the plume and up through the top window of the vacuum chamber. The scattered light was focused onto a $150 \mu \mathrm{m}$ entrance slit on a monochromator/photomultiplier tube tuned to the dye laser wavelength of $540 \mathrm{~nm}$. The recorded signal was therefore proportional to the particulate density and scattering cross section $4 \mathrm{~mm}$ in front of the aluminum target.

Figures 1(a) and 1(b) contain scanning electron microscope (SEM) pictures of two of the aluminum films depos- 


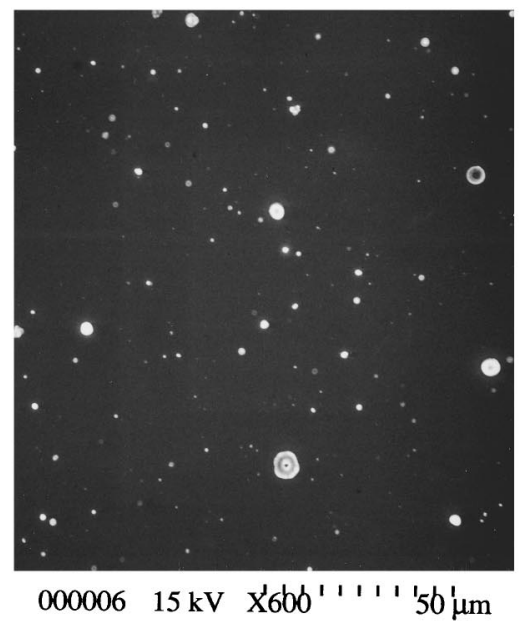

(a)

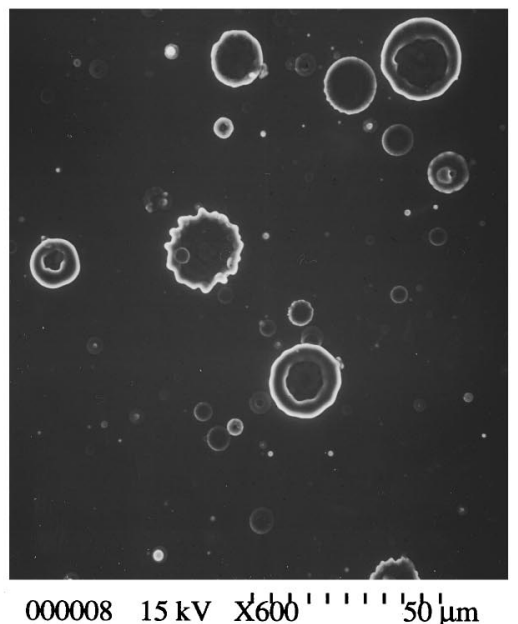

(b)

FIG. 1. SEM pictures of aluminum films produced from $1000 \mathrm{KrF}$ laser pulses at a fluence of $4.3 \mathrm{~J} / \mathrm{cm}^{2}$ as seen at $600 \times$ original magnification: (a) film produced from an undamaged target; (b) film produced from a previously damaged (1000 shots) target.

ited on silicon substrates. The film in Fig. 1(a) was produced by 1000 laser pulses on an undamaged aluminum target. For this film, the total particulate densities were on the order of $8.6 \times 10^{5} \mathrm{~cm}^{-2}$ for particulate larger than $0.5 \mu \mathrm{m}$ in diameter. In this case, no particulate larger than $15 \mu \mathrm{m}$ in diameter were observed. Figure 1(b) shows an aluminum film resulting from 1000 laser pulses on an aluminum target previously damaged with 1000 pulses. The total particulate densities in this film were on the order of $1.6 \times 10^{6} \mathrm{~cm}^{-2}$. For the film generated from a more heavily damaged target, particulate up to $20 \mu \mathrm{m}$ in diameter were observed. In comparing the photographs of each substrate, it should be noted that both the density and the size of the particulate in the film produced by the damaged target were significantly higher. The SEM pictures also illustrate the splash pattern in the aluminum particulate on the substrate surface, indicating that the incident particulate are still molten.

The density distribution per shot, obtained from optical microscope pictures, is shown in Fig. 2 for these two substrates. The chart illustrates that target damage causes par-

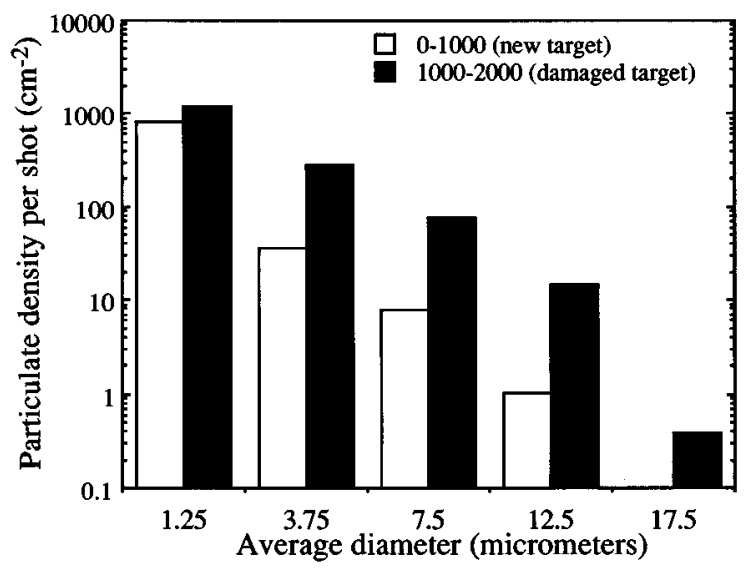

FIG. 2. Chart of particulate density per shot versus particulate size for aluminum films produced from $1000 \mathrm{KrF}$ laser pulses on damaged and undamaged aluminum targets at $4.3 \mathrm{~J} / \mathrm{cm}^{2}$.

ticulate densities to increase by factors of $\sim 10$. Average particulate diameters also increase in the range from 1.25 to $17.5 \mu \mathrm{m}$ for damaged targets.

Figure 3 shows real-time optical scattering measurements of laser ablated particulate. At each condition on the graph, starting with an undamaged target, the scattering and background signals from ten dye laser pulses were measured as a function of the time after the $\mathrm{KrF}$ excimer laser pulse. This was repeated for every point in the time scan between 20 and $240 \mu \mathrm{s}$. The points at each condition were then averaged and the standard deviation taken to find the error bars, shown at $100 \mu \mathrm{s}$ in Fig. 3. The average background signal from the PM tube was $4.8 \mathrm{mV}$, as is shown by the dashed line in Fig. 3. To advance from one stage of damage to the next, the target was ablated over 800 times at a rate of $1 / 2 \mathrm{~Hz}$ with the $\mathrm{KrF}$ laser between each data set.

The resulting data in Fig. 3 showed an increase in scattering signal with target damage to a maximum signal, $>20$ times higher than background, from a target damaged with 3000 laser pulses. At this point, the scattered signal leveled

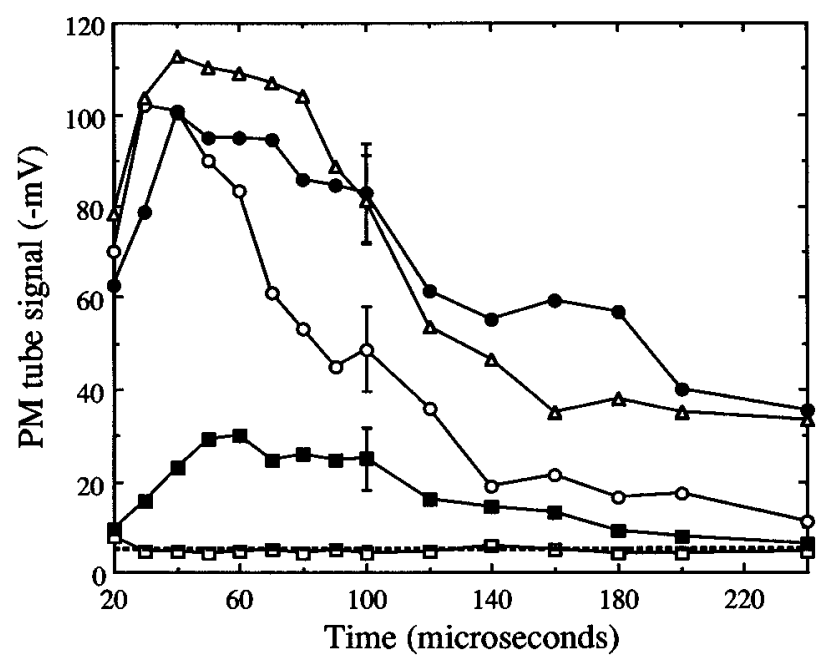

FIG. 3. Plot of dye laser scattering data at $90^{\circ}$ as a function of time after the $\mathrm{KrF}$ excimer laser ablation pulse for several levels of target damage. The background level is indicated with a dashed line: $(\square)$ undamaged target; $(\boldsymbol{\square})$ 1000 shots; (○) 2000 shots; $(\bigcirc) 3000$ shots; $(\triangle) 4000$ shots. 


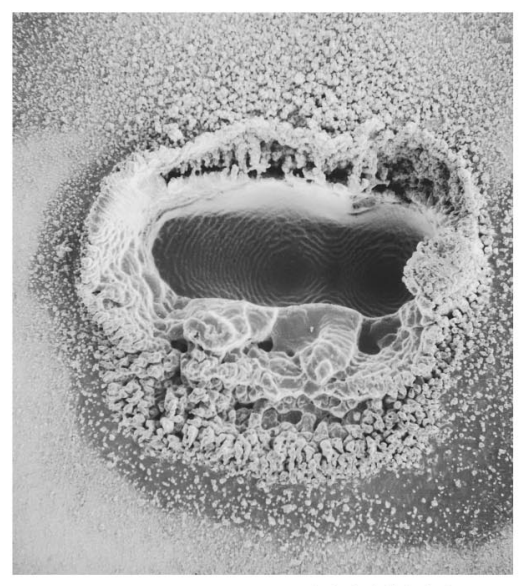

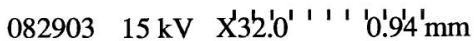

(a)

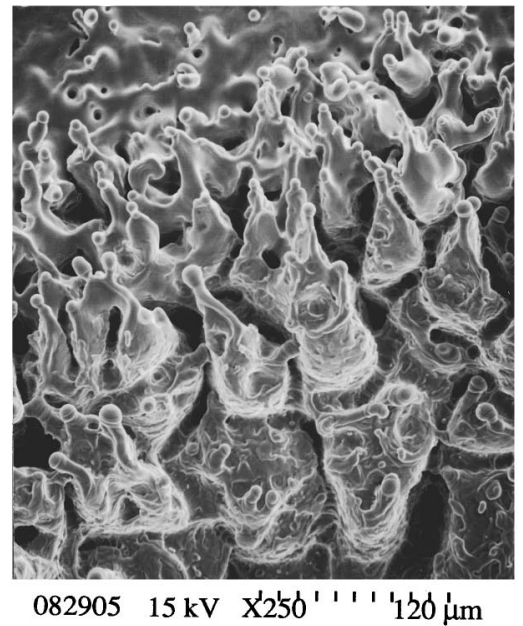

(b)

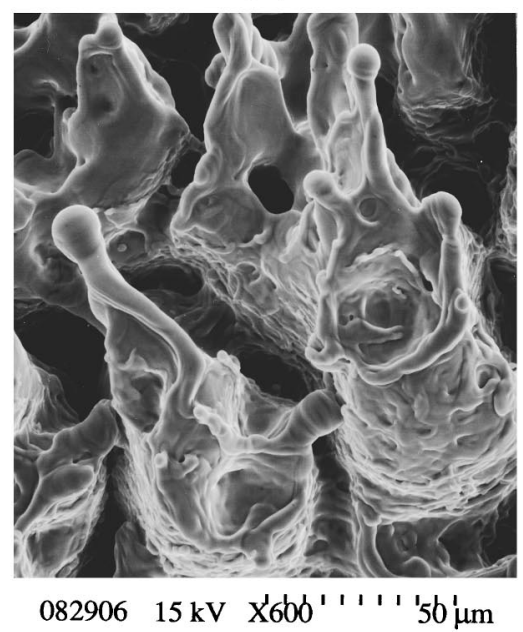

(c)

FIG. 4. Scanning electron microscope pictures of a $99.999 \%$ pure solid aluminum target with $4200 \mathrm{KrF}$ excimer laser pulses incident at a single location on the target: (a) photograph of the entire $\mathrm{KrF}$ laser spot on the target; (b) picture of the cones formed on the damaged target in the lower right of the laser spot shown in (a); (c) a magnified view of several of the cones, showing the layer of molten aluminum that was pushed up the sides and spheres on the cone tips. out and more target damage had little effect on the signal. Within each data set, the scattered signal peaked around 40 $\mu$ s. This peak in the signal was due to scattering off a high density of small particulate, translating to a speed of $\sim 100$ $\mathrm{m} / \mathrm{s}$ for the smaller particulate (probably $<0.5 \mu \mathrm{m}$ in diameter). A lower peak, appearing around $160 \mu \mathrm{s}$, was the result of the larger particulate; their velocity was a factor of 3 or 4 slower, only around $25 \mathrm{~m} / \mathrm{s}$.

Due to the random appearance of the largest particulate, the scattering signal in the later delay times $(>200 \mu \mathrm{s})$ of the graph varied widely. This led to the conclusion that the later signal was due to the largest particulate (probably 10-15 $\mu \mathrm{m}$ in diameter), which had a higher physical cross section and a much lower density and therefore a lower probability of occurrence.

Figure 4 shows scanning electron microscope pictures of the aluminum target after the scattering data was taken. There were approximately 4200 laser pulses incident on the target. Figure 4(a) contains a picture of the entire $\mathrm{KrF}$ laser spot. The deeper part of the spot indicates an area of higher fluence in the laser beam, where the bottom of the hole is relatively smooth. Figure 4(b) shows an area at the bottom right of the laser spot at a higher magnification. As a result of the large number of shots, cones formed on the target. On the tips of some of these cones, spheres of aluminum balanced, as seen more clearly in Fig. 4(c). Based on the relative diameter of the spheres on the cones $(5-15 \mu \mathrm{m})$ and the particulate in the films, it is believed that ejection of the molten material from these structures was responsible for the particulate.

This research was supported by National Science Foundation Grant Nos. CTS-9108971 and CTS-9522282. H.L.S. and J.S.L. acknowledge National Science Foundation Graduate Fellowships. The authors are grateful for equipment support from General Motors Research and Development Center.

${ }^{1}$ G. L. Doll, J. A. Sell, C. A. Taylor, and R. Clark, Phys. Rev. B 43, 6816 (1991); G. L. Doll, T. A. Perry, and J. A. Sell, Mater. Res. Soc. Symp. Proc. 201, 207 (1991).

${ }^{2}$ S. R. Foltyn, in Pulsed Laser Deposition of Thin Films, edited by D. B. Chrisey and G. K. Hubler (Wiley, New York, 1994), pp. 89-113.

${ }^{3}$ L. Ganapathi, S. Giles, R. Rao, J. P. Zheng, and H. S. Kwok, Appl. Phys. Lett. 63, 2552 (1993).

${ }^{4}$ T. Venkatesan, X. D. Wu, A. Inam, Y. Jeon, M. Croft, E. W. Chase, C. C. Chang, J. B. Wachtman, R. W. Odom, F. Radicati di Brozolo, and C. A. Magu, Appl. Phys. Lett. 53, 1431 (1988).

${ }^{5}$ S. R. Foltyn, P. Tiwari, R. C. Dye, M. Q. Le, and X. D. Wu, Appl. Phys. Lett. 63, 1848 (1993).

${ }^{6}$ H. U. Krebs and O. Bremert, Appl. Phys. Lett. 62, 2341 (1993).

${ }^{7}$ S. Witanachchi, K. Ahmed, P. Sakthivel, and P. Mukherjee, Appl. Phys. Lett. 66, 1469 (1995).

${ }^{8}$ G. Koren, R. J. Baseman, A. Gupta, M. I. Lutwyche, and R. B. Laibowitz, Appl. Phys. Lett. 56, 2144 (1990).

${ }^{9}$ C. Doughty, A. T. Findikoglu, and T. Venkatesan, Appl. Phys. Lett. 66, 1276 (1995).

${ }^{10}$ V. N. Bagratashvili, E. N. Antonov, E. N. Sobol, V. K. Popov, and S. M. Howdle, Appl. Phys. Lett. 66, 2451 (1995).

${ }^{11}$ S. M. Kimbrell and E. S. Yeung, Appl. Spectrosc. 43, 1248 (1989).

${ }^{12}$ H. C. Van De Hulst, Light Scattering by Small Particles (Wiley, New York, 1957).

${ }^{13}$ D. B. Geohegan, Appl. Phys. Lett. 62, 1463 (1993).

${ }^{14}$ J. E. Rothenburg and R. Kelly, Nucl. Instrum. Methods B 1, 291 (1984).

${ }^{15}$ R. Kelly and J. E. Rothenburg, Nucl. Instrum. Methods B 7/8, 755 (1985). 